\title{
Analysis of the effect of multi-level urban form on bikeshare demand: Evidence from seven large metropolitan areas in the United States
}

Arefeh Nasri

University of Maryland

aanasri@umd.edu

\section{Lei Zhang}

University of Maryland

lei@umd.edu

Abstract: Bikeshare programs in their current form have been in place for several years in many cities across the United States. Encouraging people to use bikeshare for their daily routine travel has numerous social, economic, environmental, and health benefits. Therefore, it is important to understand factors influencing bikeshare use in different urban areas to improve the system and encourage more use. This paper investigates how the built environment at both local and regional scales influences bikeshare use in seven large metropolitan areas in the U.S. The study areas include Boston, Chicago, Philadelphia, Minneapolis, San Francisco, San Jose, and Washington, D.C., and the data consists of about 12 million bike trips from approximately 2,000 stations over a one-year period. In addition to linear regression models built for each individual city for comparison purposes, a multi-level mixed effect regression model is built to predict the number of trips originated from each station with respect to the local and regional built environment pattern. The results are consistent with previous research on the effect of land use at the local level on bikeshare demand and show that residential density, regional diversity, pedestrian-oriented road network density, and job accessibility via transit all have a significant positive effect on bikeshare demand. At the regional level, results suggest that the overall level of mixed-use development and overall bike-friendliness in the region (i.e., exclusive bike routes, right-of-way, and bike facilities) and higher congestion level in the region are significant factors influencing bikeshare activities and demand. Models developed in this study could be applied to other communities that are seeking to improve and/or expand their bikeshare systems, as well as cities planning to launch new bikeshare programs.

Keywords: Bikeshare, urban form, multi-level built environment, demand analysis, travel behavior, mixed effect modeling

\section{Article history:}

Received: May 24, 2019

Received in revised form:

June 14, 2020

Accepted: August 12, 2020

Available online: October 29,

2020

Copyright 2020 Arefeh Nasri, Hannah Younes \& Lei Zhang

http://dx.doi.org/10.5198/jtlu.2020.1615

ISSN: 1938-7849 | Licensed under the Creative Commons Attribution - Noncommercial License 4.0

The Journal of Transport and Land Use is the official journal of the World Society for Transport and Land Use (WSTLUR) and is published and sponsored by the University of Minnesota Center for Transportation Studies. 


\section{$1 \quad$ Introduction}

U.S. households generated 4.1 billion annual bicycle trips in 2009 (Kuzmyak, Walters, Bradley, \& Kockelman, 2014). Although bicycle mode share is usually very small relative to the share of other modes such as auto and transit, it has increased from $0.7 \%$ in 1977 to about $0.9 \%$ in 2017 (Le et al., 2019). Despite this change is small, it indicates that biking has great potentials to promote sustainable travel behavior and lifestyle among American households. Promoting biking offers many benefits such as improving both physical and mental health via promoting the level of physical activity, encouraging active transportation, and reducing automobile dependency and use which would lead to less environmental emissions. Therefore, facilitating biking and proposing and implementing bike-friendly policies and programs has recently become a popular strategy for planners and policymakers to promote sustainable cities. In order to encourage more biking, the first generation of bikeshare systems was introduced in the 1960s in the Netherlands (DeMaio, 2009; Shaheen, Guzman, \& Zhang, 2010). Yet, it was the implementation of the fourth generation (the demand-responsive, multimodal systems) that made bikesharing very popular in cities all around the world; the number of cities implementing this program increased from a few cities in the Netherlands in the 1960s to more than 1000 cities worldwide by 2019.

Compared to using personal bikes, the bikeshare system makes it easier and more convenient for the users to make one-way cycling trips as part of a more complex multimodal tour without worrying about bicycle parking and theft (Gebhart \& Noland, 2014). It is a relatively cheap transportation option and could complement transit use if it is used as an access/egress mode. All these advantages made the new bikeshare systems so popular and rapidly evolving over the past several years.

In addition to various environmental and sociodemographic factors, the built environment at both local and regional levels plays an important role in determining use of a bikeshare system, as well as the distance traveled by bike and the stations to choose as pick-up and drop-off locations. At the local level, factors such as the concentration of jobs and retail/shopping opportunities around stations (Wang, Lindsey, Schoner, \& Harrison, 2015), population living within walking distance, existence and quality of sidewalks and/or bike lanes (Buck \& Buehler, 2012), and the level of street connectivity all could influence the extent to which a particular station is attracting bikeshare users. Also, the level of transit accessibility in the vicinity of bikeshare stations is a significant factor as in many cases, bikeshare could be complementary and competitive to transit use, as it allows multimodal trip-making by combining cycling and transit as well as replacing short bus trips (Younes, Nasri, Baiocchi, \& Zhang, 2019; Ma et al., 2015). At the regional level, the distribution of stations in the entire region, employment accessibility within the bikeshare system network, and the overall distribution of various destinations in the entire region could potentially influence the quality and frequency of using the bikeshare system for a particular trip or as a routine daily commute mode by an individual. Many previous studies have shown that the built environment at the stations' vicinities influences bikeshare stations' activities (i.e., total number of trips originated or the average daily frequency of trips to/from stations). In this paper, we examine the effect of built environment at both local vs. regional levels as we hypothesize that in addition to the environment surrounding stations, a particular station's activity could also be influenced by the overall urban form and accessibility pattern of the metropolitan area where the station is located. In addition, there are interactions among stations and the spatial structure of the stations' network, their capacity, and distance between them would also influence the frequency of usage at each station.

The main objective of the current analysis is to explore and quantify the influence of various built environment factors on bikeshare usage in seven U.S. metropolitan areas using a spatial-statistical approach to measure the built environment at multiple scales. The choice of these cities with varying characteristics in terms of size, geographical location, and urban form allows for a more comprehensive 
analysis of the effects of urban form at multiple scales on bikeshare usage. To capture both local and regional effects, we used measures such as residential and employment densities, level of mixed-use and regional land-use diversity, job accessibility within a certain travel time (distance), road network density, and rail transit accessibility to account for these effects at the station level. We also provided measures of overall mixed-use development, walkability, employment accessibility through bikeshare systems, and the proportion of population living within an easy access to the bikeshare network throughout the entire metropolitan areas to address the regional effects.

\section{$2 \quad$ Literature review}

Similar to personal bike mode choice, many factors contribute to the choice of bikeshare system as a travel mode and the frequency of using the system as indicated in the literature. These factors include the socio-demographic characteristics of the users such as age, income, gender, education level, car ownership, working status, and the possession of a driver's license (Buehler, 2011; Kuzmyak et al., 2014; Buck \& Buehler, 2012; Fishman, 2016), road safety and weather conditions (Rodríguez \& Joo, 2004; Parkin, Wardman, \& Page, 2008; Gebhart \& Noland, 2014; Buck \& Buehler, 2012), accessibility to other modes, system characteristics such as the location and spatial distribution of docking stations, and the system's capacity (Biehl, Ermagun, \& Stathopoulos, 2018). Other factors to consider are the trip purpose, activity to be reached at destination, the characteristics of the origin-destination travel path (or road network), the travel path's topography (presence of hills, etc.)

Several studies show that bikesharing trips are made for both work and non-work trips almost equally in large cities (Martin \& Shaheen, 2014; Shaheen, Cohen, \& Martin, 2013). Public bikes are also largely used as a first-mile, last-mile mode to facilitate access to and from public transit, especially in areas with less extensive transit networks (Martin \& Shaheen, 2014; Tingting, Li, \& Wei, 2011). Accessibility to docking stations (i.e., greater number of docking stations near home and work locations) and an efficient spatial distribution of stations (a well-connected bikesharing network) throughout the metropolitan area play major roles in increasing a system's use. The built environment in the areas surrounding the stations is another significant factor influencing a person's decision to use a bikeshare system, both as a primary travel mode for short trips or as a complementary mode for longer transit trips. While there is a plenty of research in the body of literature on the effect of built environment on increased non-motorized mode share worldwide (Guan, Srinivasan, \& Nielsen, 2019; Nielsen \& SkovPetersen, 2018; Rajamani, Bhat, Handy, Knaap, \& Song, 2003), this relationship was not investigated specifically for the bikeshare systems until very recently.

Many previous studies have focused on the effect of urban form around docking stations and its influence on bikeshare use. For instance, Wang et al. (2016) investigated the effect of job density and businesses near stations on annual usage in Minneapolis and found that the number of trips to and from bikeshare stations is significantly associated with neighborhood socio-demographics, proximity to the city center and economic activities, accessibility to trails, and distance to other bikeshare stations. Hampshire and Marla (2012) also found that population and employment densities are highly correlated with a higher system use in Barcelona, Spain (Hampshire \& Marla, 2012). Buck and Buehler (2012) performed a similar analysis for the Washington, D.C. bikeshare system and suggested that there is a statistically significant relationship between the bike lane supply and the number of bikesharing trips, after controlling for population, retail densities and car ownership. Again, using Washington, D.C. bikeshare as a case study, Gehrke and Welch (2019) applied latent class cluster analysis method and identified five different station area types based on land development pattern, urban design, and transportation supply and infrastructure. They used a variety of built environment measures from Census 
and LEHD data sources to develop this typology and used in for the purpose of planning for expansion and forecasting the demand in the proposed and planned new stations. Rixey (2013) did a comparative analysis for the effects of land use on a bikeshare stations' activity in three U.S. cities and found that population and job densities, as well as the income levels of the users and the availability of alternative modes, all significantly affect bikesharing usage (Rixey, 2013). Faghih Imani, Eluru, El-Geneidy, Rabbat, \& Haq (2014) focused on the effects of land use on bicycle flows for the Bixi system in Montreal, Canada, and suggested that station proximity to major roads negatively influences the ridership; also in addition, a higher number of stations close to each other would increase the public bikes' usage in the system (Faghih Imani et al., 2014). Mateo-Babiano, Bean, Corcoran, and Pojani, (2016) investigated the joint effects of built environment, biking infrastructure, and topography on bikesharing demand in Brisbane, Australia and found that bikesharing usage is significantly correlated with the length of offroad bikeways near each station and in general, the stations located in the city center are more active and those located in the hilltops are less active.

Many studies also investigated the effect of bikesharing stations' accessibility to transit network as well as to other bikesharing stations, and suggested that ridership is positively associated with the stations' proximity to transit stops (Nair, Miller-Hooks, Hampshire, \& Bušić, 2013; El-Assi, Mahmoud, \& Habib, 2017; Tran, Ovtracht, \& d'Arcier, 2015) and other bikesharing docking stations (Morency, Trépanier, Faucher, Páez, \& Verreault, 2017; Bachand-Marleau, Lee, \& El-Geneidy, 2012). Martin and Shaheen (2014) investigated transit ridership in response to bikesharing systems in Washington, D.C. and Minneapolis, MN. The study found that the shift toward using public transit is observed more in low-density, suburban areas whereas in high-density areas, bikesharing is more abundant, shifting people away from transit use. In addition, Bachand-Marleau, Lee, and El-Geneidy (2012) suggested that increasing the number of docking stations in residential areas would encourage more people to use the system.

Despite useful findings and policy recommendations made by these papers, they have limitations. First, their built environment measures are mostly limited to population and job densities, number and length of bike lanes, and some approximate measures for accessibility and level of mixed-use development (Buck \& Buehler, 2012; Martin \& Shaheen, 2014). Second, in many of these past studies, the time period for the analysis was narrowed down to one day or one month-typically in summer-or a short period of time (Buck \& Buehler, 2012; Jäppinen, Toivonen, \& Salonen, 2013; Muarer, 2011). Also, the potential impact of the overall urban form at regional and metropolitan levels was not studied previously, as most of the analyses in the field are limited to only one city. To the best of authors' knowledge, and as it appears in the body of the literature, there are very few studies that investigate the effect of built environment at different geographical levels on bikesharing demand in multiple cities, especially in the United States (Martin \& Shaheen, 2014; Rixey, 2013; Ranaiefar \& Rixey, 2016). For instance, Ranaiefar and Rixey (2016) developed a structural equations model to estimate the effect of the built environment surrounding bikesharing stations in four U.S. cities on bikesharing ridership and included measures of built environment at both origin and destination for each trip. Other studies such as Rixey (2013) and Martin and Shahin (2014) provided a comparative analysis of bikeshare systems between only two cities. The present study contributes to the literature by exploring the associations between built environment at multiple scales and bikesharing usage in seven U.S. metropolitan areas with relatively large bikesharing systems and allows for a comparative analysis aiming for more efficient planning operation and expansion of bikesharing systems across the country. 


\section{$3 \quad$ Methodology}

\subsection{Data and variable construction}

Several measures of the built environment have been considered in the current study including: residential and employment densities; the level of mixed-use development and regional diversity; road network density (both auto- and pedestrian-oriented roads); street connectivity; transit accessibility; multi-modal job accessibility; walkability; the bikeshare system's accessibility; and measures on the overall bike friendliness and congestion level.

The built environment data for each case study area is obtained and extracted from the Smart Location Database (SLD), a publicly available dataset developed by the Environmental Protection Agency (EPA) for the entire U.S. The SLD provides a wide range of land-use measures at the census block group (CBG) level and several aggregated socioeconomic and demographic measures for the entire nation. The availability of SLD for all metropolitan areas across the country eliminates the data consistency issue faced in many previous multi-city studies. The Geographic Information System (GIS) was employed to spatially link the bikeshare station data to the SLD to obtain land-use measures associated with each station and resolve some minor data consistency issues. Other data sources, such as Census/TIGER data, Congestion index data, IPUMS data, and the walk score data, were also used to calculate aggregate sociodemographic data as well as variables such as block size, walkability/bikability score, and congestion scores.

Table 1 presents definitions of all variables considered for the analysis along with their data sources. The independent variables are measured at two levels: local level (i.e., either the station level or the census block group where the station is located), and regional level (i.e., the county or metropolitan area where the station is located). As shown in Table 1, most of the local-level variables are either directly obtained from or calculated based on measures provided by the SLD. Variables at the regional level are either calculated directly for the entire region, or are based on aggregated measures at the census block group level using spatial analysis techniques. In addition to the built environment variables, some aggregated measures of socioeconomic and demographic characteristics of the census block group level are provided and used in our models. Also, station capacity and the percentage of days the station was in service are added as control variables. 
Table 1. Variables and data sources

\begin{tabular}{|c|c|c|}
\hline Variables & Description & Data Source \\
\hline \multicolumn{3}{|l|}{ Dependent Variable } \\
\hline \multicolumn{2}{|c|}{ Number of Trips Originated From Each Station in 2018 (log-transformed) } & CityBikeshare \\
\hline \multicolumn{3}{|c|}{ Variables Measured at the Station Level } \\
\hline Station capacity & Number of docks available in each station & CityBikeshare \\
\hline Active-days & Percentage of days the station was active in 2018 & CityBikeshare \\
\hline Rail-access & $\begin{array}{l}\text { Presence of rail station within } 0.1 \text { mile of bikeshare station; } \\
\text { dummy variable }\end{array}$ & Bikeshare data/Rail transit data \\
\hline \multicolumn{3}{|c|}{ Variables Measured at the Census Block Group (CBG) Level } \\
\hline Zero-car population & Percentage of CBG population with 0 cars & SLD \\
\hline 2plus-car population & Percentage of CBG population with 2 or more cars & SLD \\
\hline Total population & Total population of the CBG, 2010 & SLD \\
\hline$\%$ White population & $\% \mathrm{CBG}$ population that is white & IPUMS database \\
\hline $\begin{array}{l}\% \text { Residents with bachelor's } \\
\text { degree or higher }\end{array}$ & \% CBG residents with a bachelor's degree or higher & IPUMS database \\
\hline Median household income & Median household income in the CBG-2017 (1000s) & IPUMS database \\
\hline Residential density & Number of people per acre in the CBG & SLD \\
\hline Employment density & number of jobs per acre in the CBG & SLD \\
\hline Avg. block size & Average block size- square mile & Census/TIGER 2010 \\
\hline Regional diversity & $\begin{array}{l}\text { employment: Deviation of CBG ratio of jobs/pop from } \\
\text { regional average ratio of jobs/pop }{ }^{1}\end{array}$ & SLD \\
\hline Entropy & Level of land-use mix using 5 employment types & SLD \\
\hline Network density-pedestrian & Facility miles for pedestrian-oriented links per sq. mile & SLD \\
\hline Transit-accessible jobs & Jobs within 45-minute transit commute & SLD \\
\hline Auto-commuter population & Working-age population within 45-minute auto commute & SLD \\
\hline Transit-shed jobs & Proportion of $\mathrm{CBG}$ jobs within $1 / 2$ mile of transit & SLD \\
\hline \multicolumn{3}{|c|}{ Variables Measured at the Metropolitan Level } \\
\hline Residential-bikeshare & $\%$ population with access to bikeshare system & SLD/ Bikeshare data \\
\hline Employment-bikeshare & $\%$ jobs with access to bikeshare system & SLD/Bikeshare data \\
\hline \%small blocks & $\%$ of blocks smaller than 0.01 sq. $\mathrm{mi}$ in the metro area & Census/TIGER 2010 \\
\hline Avg residential density & Average population density per sq. miles & SLD \\
\hline Avg employment density & Average employment density, sq. miles & SLD \\
\hline Avg entropy & Average level of mixed use development & SLD \\
\hline Avg auto-commuter population & $\begin{array}{l}\text { Average working-age population within } 45 \text {-min auto com- } \\
\text { mute in the county }\end{array}$ & SLD \\
\hline Bikability score & Overall bike-friendliness of the metropolitan area & Walkscore Inc. \\
\hline Congestion index & Level of congestion over the metropolitan area & TTI congestion index dataset ${ }^{2}$ \\
\hline
\end{tabular}

${ }^{1}$ Land-use diversity refers to the relative mix of land uses within a zone of analysis. There are a number of different ways to measure the mix of land uses such as 1) Entropy, which measures how equally different types of land use are mixed within a geographic unit (Nasri \& Zhang, 2012; Zhang, Hong, Nasri, \& Shen, 2012; Frank, Schmid, Sallis, Chapman, \& Saelens, 2005; Christian et al., 2011), and 2) Regional diversity, which is calculated based on total population and total employment by CBG. It quantifies the deviation of the CBG ratio of jobs/pop from the regional average ratio of jobs/pop. It is calculated using this formula: Regional Diversity= $1-\mid\left(b^{*}(\right.$ TotPop-TotEmp $\left.)\right) /\left(b^{*}(\right.$ TotPop+TotEmp $\left.)\right) \mid$ Where: $b=$ Regional population/ Regional employment.

${ }^{2}$ Schrank and Lomax (2007) 
The dependent variable used in our model is the number of total trips originated from each bikeshare station during the entire year of $2018 .{ }^{3}$ We used log transformation because (1) the dependent variable follows a log-normal distribution and (2) to address heteroskedasticity issues. The trip records for each study area are obtained from their bikeshare system's website. These datasets are publicly available for multiple years (for the entire operation period for each city). For the current study, we used the 2018 data for all cities. Data for each trip record includes the trip origin and destination station location, start/end date and time, the user type (subscriber vs. casual user), and station capacity (i.e., number of docks available-either empty or full). Trips starting and ending at the same station that lasted less than three minutes were considered invalid trips and were removed from the dataset (These are most likely the result of someone unlocking a bike and then changing their mind and return it without actually taking a bike trip). After removing the invalid trips and the observations with missing values, the dataset includes 2,130 observations (bikeshare stations) located in seven metropolitan areas. In the following section, the case study areas and their bikeshare system's characteristics are reviewed in terms of the current state of the bikesharing usage in each city and how they are similar and/or different.

\subsection{Multi-level mixed effect modeling approach}

To investigate the effect of both micro- and macro-level built environment on bikeshare demand, the multi-level mixed effect regression modeling approach was taken using $\mathrm{R}$ (Team, 2012) and the lme4 package (Bates, Maechler \& Bolker, 2012). Our built environment variables are measured at both census block group and regional levels. The mixed effect model has two separate parts: the fixed effects and the random effects. Similar to linear regression models, the fixed effect only captures the linear correlations among the dependent and the explanatory variables with some coefficient estimates - which is the part of the relationship that we understand and measure; and an error term " $\varepsilon$ " - which is the part we cannot control or measure. The random effect is added to the model to give a structure to the error term $\varepsilon$ and help us better understand the variations. As fixed effect, we entered the aggregated socio-demographic and car ownership characteristics, as well as the built environment measures such as residential density, employment density, level of mixed-use and regional land-use diversity, road network density, etc. at the station and CBG levels and several built environment measures at the regional (county and metropolitan) levels.

As for the random effect, we considered the CBG where the observation (here each bikeshare station) is located and the city where the station is located to have some random effect on the bikeshare demand. In the dataset, there are multiple bikeshare stations located in the same $\mathrm{CBG}$ - or the same city - which share the same built environment characteristics. The trips originated from stations located within the same CBG are assumed inter-dependent rather than independent. The reason for this inter-dependency is that the trips to and from each station is to some extent affected by the activity of the nearby station as well. For instance, if a station is empty of available bikes or full of returned ones, potential riders will have to go to a nearby station in case they want to check out or return a bike. Additionally, since the majority of the bikeshare trips are short in both length (usually less than or equal to thirty minutes) and distance (usually between 1-4 miles), the stations located nearby influence activities of one another as bikes are frequently exchanged (i.e., check out and returned) among the neighboring stations and therefore influence the activities of one another. We deal with the inter-dependency between stations located in the same CBG adding a random effect for the CBG and assuming different intercept value for each CBG. Similarly, we added a separate random effect for the city where the

\footnotetext{
${ }^{3}$ Except for the Minneapolis case, which does not operate the entire year. The data used for Minneapolis includes the last operation period for which the data was available: April- November 2018.
} 
station is located to test whether stations located within the same city are inter-dependent as well. The hypothesis is that a particular station's activity is also influenced by the overall bikeshare network of the city and its characteristics such as the overall number of stations, the fleet size, the spatial distribution of the stations across the city, and its coverage and accessibility to various destinations, jobs, and transit network. Therefore, our model allows for each CBG and city ID to have a different intercept value and the mixed effect model estimates these varying intercepts. Mixed effect model allows us to capture both fixed and random effects. It is formulated as follows:

$$
\operatorname{LogTrip}_{i j c}=S E S_{j}+S E S_{C}+B E_{j}+B E_{C}+(1 \mid \mathrm{CBG}, \text { City })+\varepsilon
$$

where:

LogTrip ${ }_{i j c}=$ Number of trips originated from station $i$ (Log-transformed)

$S E S_{j}=$ Aggregated Socioeconomic status of $C B G j$ where station $i$ is located

$S E S_{c}=$ Aggregated Socioeconomic status of City $c$ where station $i$ is located

$B E_{j}=$ Built environment characteristics of $C B G j$ where station $i$ is located

$B E_{C}=$ Built environment characteristics of City $c$ where station $i$ is located

$\varepsilon=$ Random error term

The error term at the end is still necessary. After the individual by-CBG variation is accounted for using the random affect, there is still going to be "random" differences between different stations from the same CBG. Our mixed effect model specification has resolved the non-independencies among stations within the same $\mathrm{CBG}$ and both the by-CBG and by-station variations are accounted for in the current model.

\section{$4 \quad$ Results}

\subsection{Descriptive analysis}

In total, there are 2,130 stations in our sample. Table 2 below summarizes the stations' characteristics and bikesharing activities in all seven case study areas. As it indicates, Chicago has the largest bikeshare system among all seven areas, with over $500^{4}$ stations and close to 6,000 bikes. All systems are operating year-round, except for Minneapolis, which operates from April-November each year and closes the rest of the year due to inclement weather conditions.

These cities are selected for the analysis based on two factors: size and urban form. All seven cities are among the largest bikeshare systems in the U.S., and they have different urban form patterns in terms of population and employment densities, accessibility measures, and connectivity, as well as their different geographical location and climate conditions. Comparison of these cities in terms of the level of bikeshare usage would enable a better understanding of the factors influencing demand at the station level, and eventually will be useful in systems' operation and planning for system expansions as well implementation of the bikeshare program in other cities.

After removing the invalid trips, the total number of trips made in Chicago in 2018 was 3,603,082, which is slightly higher compared to the number of trips in Washington, D.C. Boston and San Francisco-San Jose both generated within the range of 1.8 million trips in 2018, and Minneapolis and Philadel-

${ }^{4}$ Chicago has 516 stations that are active 330+ days annually, of which 475 stations are active $350+$ days. 
phia generated around 400k and 700k trips in 2018, respectively. The average number of trips generated per station on a monthly basis is within the same range in Minneapolis and Philadelphia (between $51 \mathrm{k}$ 56k). Among the other study areas, Boston had the lowest, with 147,317 average monthly trips, and Chicago had the highest record, with more than 300,000 average monthly trips (slightly higher than the average monthly trips in Washington, D.C).

To measure the overall proximity of the bikeshare network to the rail transit network in each city, we calculated the percentage of bikeshare stations located within $1 / 2$ mile of transit stops. As indicated in Table 2, about $80 \%$ of bikeshare stations in Philadelphia and Boston, and $70 \%$ of the stations in Chicago and San Francisco-San Jose have good access to the transit network (i.e., located within $1 / 2$ miles of rail transit stops), whereas this number is $62 \%$ in Washington, D.C. These numbers indicate that in all study areas, the majority of the bikeshare stations are located in close proximity to transit network, hoping for a better integration and higher efficiency and use of these two sustainable modes.

Table 2. Bikeshare systems' characteristics and summary

\begin{tabular}{|c|c|c|c|c|c|c|}
\hline System & Boston & Chicago & Minneapolis & Philadelphia & $\begin{array}{l}\text { San Francisco } \\
\text { \& San Jose }\end{array}$ & $\begin{array}{l}\text { Washington, } \\
\text { D.C. }\end{array}$ \\
\hline Launch date & July 2011 & Jun. 2013 & Jun. 2010 & Apr. 2015 & Aug. 2013 & Sep. 2010 \\
\hline $\begin{array}{l}\text { Annual mem- } \\
\text { bership }\end{array}$ & $\$ 99$ & $\$ 99$ & $\$ 75$ & $\$ 156$ & $\$ 149$ & $\$ 85$ \\
\hline Name & BlueBikes* & Divvy & NiceRide & Indego & Ford GoBike & $\mathrm{CaBi}$ \\
\hline \# of stations & 310 & 475 & 198 & 131 & 320 & 528 \\
\hline $\begin{array}{l}\text { Avg Station } \\
\text { Capacity }\end{array}$ & 17 & 17 & 17 & 21 & 21 & 17 \\
\hline Total \# of bikes & $2,500+$ & 5,800 & 3,000 & $1,000+$ & 7000 & 4,300 \\
\hline $\begin{array}{l}\text { \# of trips } \\
(2018)^{* *}\end{array}$ & $1,767,806$ & $3,603,082$ & 412,423 & 671,818 & $1,863,721$ & $3,542,684$ \\
\hline $\begin{array}{l}\text { Average } \\
\text { monthly trips } \\
(2018)\end{array}$ & 147,317 & 300,256 & 51,552 & 55,984 & 155,310 & 295,223 \\
\hline $\begin{array}{l}\% \text { stations } \\
\text { within } 1 / 2 \text { mile } \\
\text { of transit }\end{array}$ & 80.1 & 71.0 & 47.8 & 80.6 & 70.5 & 62.1 \\
\hline
\end{tabular}

Figure 1 presents the total number of monthly trips in all case study areas. As it indicates, June-August have the highest bikeshare demand in all seven cities and November-February period attracts the least number of trips by the bikeshare system's users. This proves weather as a significant factor influencing the bikeshare demand in different areas as also stated in previous studies (Gebhart \& Noland, 2014; Younes, Zou, Wu, \& Baiocchi, 2020). As a result, in inclement weather conditions during the coldest months, people who previously used bikeshare would switch to other modes (Gebhart \& Noland, 2014; El-Assi et al., 2017; Morency et al., 2017). The chart in Figure 1 also indicates that Divvy system in Chicago is the most active system among all seven cities with the highest number of trips year-round, even though the overall weather conditions in Chicago are less bike-friendly than other cities such as Washington, D.C. and Philadelphia. However, Chicago has the largest bikeshare network among all seven study areas. Therefore, the size of the bikeshare system in place is a significant factor influencing the overall accessibility to the system and thus higher number of trips made. 


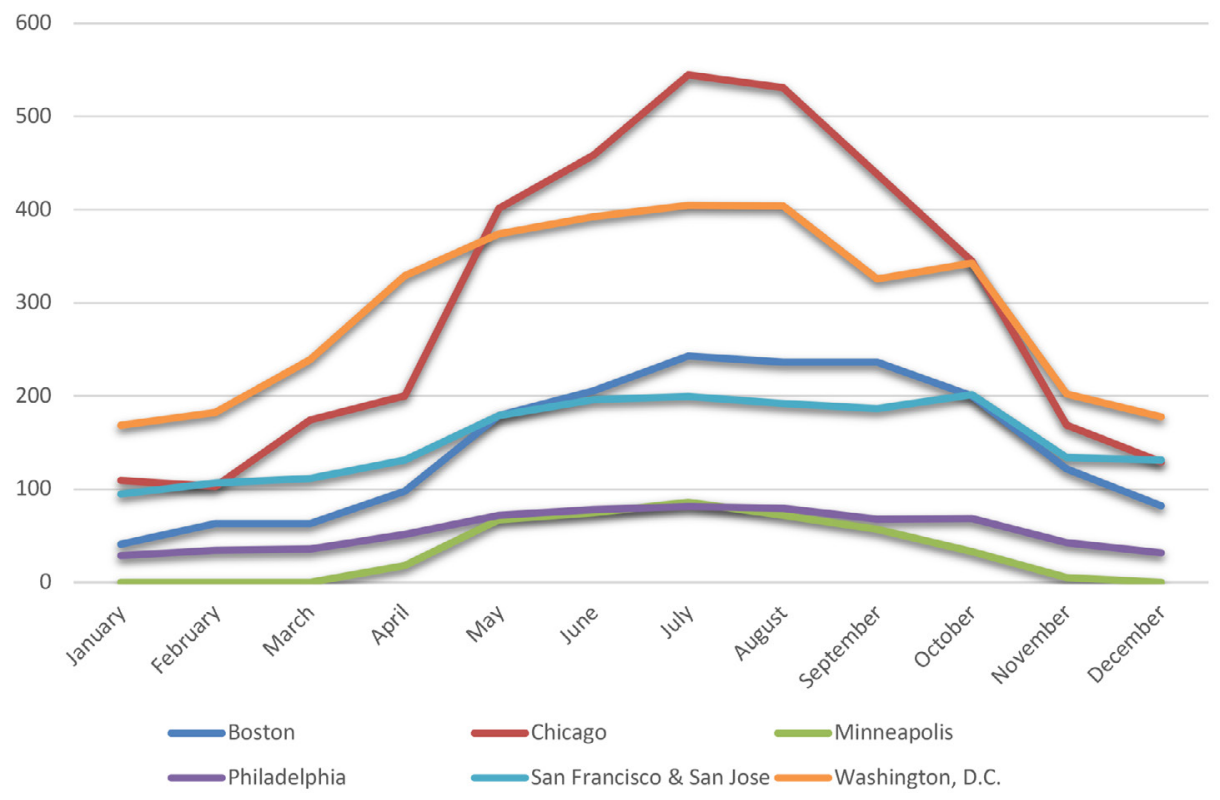

Figure 1. Monthly trip trend in 2018 (\#trips by 1000s)

\subsection{Statistical and multi-level analysis}

The results of the mixed-effect model are presented in Table 3 and show both fixed effect coefficients for each individual variable and random effect for the CBG and City. The fixed effect coefficients reflect the output that we would expect if we run a linear regression model. The random effect is presented by intercept and residual values. Standard deviation of the intercept is a measure of how much variability in the number of trips originated from station $i$ there is due to the characteristics of the CBG where station $i$ is located as well as the city where station $i$ is located. The residual shows the variability that is not due to the random effect variable. It is the $\varepsilon$ in the formula above and measures the random deviations from the predicted values that are not due to CBG. We also tested for multi-collinearity among the independent variables through constructing the correlation matrix and found that the correlations among variables that are included in the final model are very small and negligible.

Results indicate that the station capacity and the percentage of days the station was active in 2018, are both significantly and positively correlated with the number of trips originated from bikeshare stations. Moreover, the binary variable showing existence of at least one rail transit stop within a half-mile buffer distance of docking stations shows a significant positive correlation with the number of trips at the station level, implying the complementary relationship between bikeshare system and transit. Bikeshare trip generation shows significant positive correlation with the proportion of zero-car households and significant negative correlation with households with two or more cars. The coefficients imply that, because of the log-linear relationship in the model, a $1 \%$ increase in zero-car households and a $1 \%$ increase in 2 or more car households is associated with a $1.53 \%$ increase and a $0.56 \%$ decrease in bikeshare trips, respectively.

Regarding the local effect, most of the variables are significantly correlated with the stations' ridership. Residential density, regional land-use diversity, and pedestrian-oriented network density all positively influence the stations' activity. Similarly, the higher proportion of working-age population within 
45-minute auto commute and Proportion of station area jobs within $1 / 2$ mile of transit are both associated with the higher number of trips originated from stations.

As it is indicated in Table 3, most of the regional-level measures are either eliminated from the model or do not show statistically significant association with the bikeshare demand, except for overall level of mixed-use development and the proportion of working-age population within a 45-minute auto commute over the entire metropolitan area, which both show significant positive association with bikeshare demand. Moreover, the overall metropolitan area's Bikeability and the overall congestion level only show marginally significant positive relationship with the station-based bikeshare demand.

This implies that even though some regional characteristics influence the station-level bikeshare demand, the bikeshare activity in a particular station is not necessarily correlated with the overall built environment pattern to the extent it is correlated with the built environment and accessibility measures of the immediate neighborhood of that particular station. This is contrary to the findings for other modes such as driving and transit, as previous research suggested (Nasri, 2016). It might be because bike trips are usually shorter compared to auto and transit trips and thus most bike trips would likely occur in a single neighborhood. Therefore, bike trips are not as influenced by the large-scale urban form pattern, even though some regional factors, such as the overall level of mixed-use development, overall bike friendliness, and congestion level would slightly influence the bikeshare demand at station levels.

In short, the results suggest that providing higher level of land-use mix all over the metropolitan areas-not just within specific neighborhoods - would significantly influence the demand for sustainable modes such as biking. Higher level of congestion is a significant factor encouraging people to switch to other modes including bikeshare as well, and providing a bike-friendly environment through the entire metropolitan area by providing exclusive bike lanes/paths, bicycle right-or-way, and shared-use streets with adjusted speed limits would all promote the usage of bikeshare systems for various trip purposes. 
Table 3. Multilevel mixed effect regression model—all cities

\begin{tabular}{|c|c|c|c|}
\hline \multicolumn{4}{|l|}{ Dependent variable: $\log$ (trips) } \\
\hline Variable & Coefficient & Std. Error & $\operatorname{Pr}(>|t|)$ \\
\hline \multicolumn{4}{|l|}{ Fixed Effects } \\
\hline Intercept & $-1.011 e+01$ & $2.58 \mathrm{e}+00$ & $0.043 *$ \\
\hline \multicolumn{4}{|l|}{ Station-level Variables } \\
\hline Station capacity & $4.46 \mathrm{e}-02$ & $2.84 \mathrm{e}-03$ & $<2 \mathrm{e}-16^{* * *}$ \\
\hline Active days & $3.14 \mathrm{e}+00$ & $8.24 \mathrm{e}-02$ & $<2 \mathrm{e}-16^{* * *}$ \\
\hline Rail-access & $1.32 \mathrm{e}-01$ & $4.13 \mathrm{e}-02$ & $0.0014^{* *}$ \\
\hline \multicolumn{4}{|l|}{ Socio-demographic Variables } \\
\hline Zero-car population & $9.31 \mathrm{e}-01$ & $1.64 \mathrm{e}-01$ & $1.60 \mathrm{e}-08^{* * *}$ \\
\hline 2plus-car population & $-8.27 e-01$ & $1.89 \mathrm{e}-01$ & $1.33 \mathrm{e}-05^{* * *}$ \\
\hline Total population & $5.37 \mathrm{e}-05$ & $2.43 \mathrm{e}-05$ & $0.027^{*}$ \\
\hline$\%$ White population & $8.72 \mathrm{e}-01$ & $1.22 \mathrm{e}-01$ & $1.81 \mathrm{e}-12^{* * *}$ \\
\hline $\begin{array}{l}\% \text { Residents with bachelor's } \\
\text { degree or higher }\end{array}$ & $1.97 \mathrm{e}+00$ & $1.47 \mathrm{e}-01$ & $<2 \mathrm{e}-16^{* * *}$ \\
\hline Household annual income & $-4.60 \mathrm{e}-07$ & $7.92 \mathrm{e}-07$ & 0.56 \\
\hline \multicolumn{4}{|l|}{ BE Variables at the CBG Level } \\
\hline Residential density & $4.58 \mathrm{e}-03$ & $8.26 \mathrm{e}-04$ & $3.51 \mathrm{e}-08^{* * *}$ \\
\hline Employment density & $-1.098 \mathrm{e}-04$ & $2.073 \mathrm{e}-04$ & $0.0011^{* *}$ \\
\hline Regional diversity & $1.79 \mathrm{e}-01$ & $8.41 \mathrm{e}-02$ & $0.033^{*}$ \\
\hline Network density-pedestrian & $1.21 \mathrm{e}-02$ & $2.95 \mathrm{e}-03$ & $4.55 \mathrm{e}-05^{* * *}$ \\
\hline Auto-commuter population & $5.26 \mathrm{e}-06$ & $3.65 e-07$ & $<2 \mathrm{e}-16^{* * *}$ \\
\hline Transit-shed jobs & $1.49 \mathrm{e}-01$ & $5.85 \mathrm{e}-02$ & $0.011^{*}$ \\
\hline \multicolumn{4}{|c|}{ BE Variables at the Regional Level } \\
\hline Avg entropy & $1.18 \mathrm{e}+01$ & $2.35 e+00$ & $0.030 *$ \\
\hline $\begin{array}{l}\text { Auto-commuter population- } \\
\text { county }\end{array}$ & $3.86 \mathrm{e}-06$ & $6.89 \mathrm{e}-07$ & $2.62 \mathrm{e}-08^{* * *}$ \\
\hline \%small blocks & $-5.91 \mathrm{e}-02$ & $1.59 \mathrm{e}-02$ & $0.047^{*}$ \\
\hline Bikeability score & $5.18 \mathrm{e}-02$ & $1.75 \mathrm{e}-02$ & 0.073 \\
\hline Congestion index & $2.059 \mathrm{e}+00$ & $7.22 \mathrm{e}-01$ & 0.096 . \\
\hline \multicolumn{4}{|l|}{ Random Effects } \\
\hline & Variance & Std. Dev. & \\
\hline Intercept (CBG) & 0.32 & 0.57 & \\
\hline Intercept (City) & 0.053 & 0.23 & \\
\hline \multirow[t]{2}{*}{ Residual } & 0.26 & 0.51 & \\
\hline & Marginal & Conditional & \\
\hline R-squared & 0.76 & 0.904 & \\
\hline Significance level: $0^{(* * *)} \quad 0$. & $\begin{array}{lll}01^{(* *)} & 0.01^{(*)} & 0.05^{\prime} !\end{array}$ & & \\
\hline
\end{tabular}

For the random effect, we allow only the intercept to vary across the clusters (here both the CBGs and the cities as clusters). The random component displays the variances and standard deviation of the random intercepts. As it is shown in the Table 4, the variance of the intercept for the CBGs is 0.32 and for the City is 0.053 , meaning that there is a higher variation of the intercepts between the census 
block groups than between the cities, which implies that cities as a whole show similar bikeshare trip demand whereas CBGs show different pattern as they have different locations, land-use pattern, and sociodemographic characteristics. R-marginal and R-conditional are proportion of reduced error, or pseudo- $R^{2}$. R-marginal is the variance explained by the fixed effects over the total (expected) variance of the dependent variable. The R-conditional is the variance explained by the fixed and the random effects together over the total (expected) variance of the dependent variable. In our example, the fixed effects explain $76.0 \%$ of the variance, whereas the overall model (fixed + random) captures a considerably big share of the variance $(90.4 \%)$.

Table 4 provides marginal effects of selected variables in the model and highlight the differences of the magnitude of the effects. These marginal effects are easier to understand and interpret compared to elasticities due to the log-linear nature of the model and the fact that several variables in the model are percentages rather than absolute values. As indicated in Table 4, increasing the capacity of the docking stations is one of the most influential factors on bikeshare demand (one added dock would result in $4.5 \%$ increase in the number of trips originated from a station). As expected, zero-car households and households with two or more cars have opposite effects on bikeshare trip generation. However, the proportion of zero-car households is a larger driver of trip fluctuations than households with two or more cars. A $1 \%$ increase in the proportion of people near half a mile of a transit stop is associated with a $0.16 \%$ in trips. While this is a small increase, it is a valuable finding in that it helps to indicate that people who live near transit are more likely to use bikeshare. In terms of population, the population of a census block group has a large marginal effect of $5.4 \%$ added trips for every 1000 people. In comparison, percentage of working-age residents within a 45-minute auto travel time increases bikeshare trips by $0.52 \%$. Finally, a $1 \%$ increase in the population with a bachelor's degree or higher is associated with a nearly $2 \%$ increase in trips. This increase is larger than that of race/ethnicity, which is associated with $0.87 \%$ and that of income, which is insignificant in our model.

Table 4. Marginal effects of selected variables

\begin{tabular}{lll}
\hline & Increase in Independent Variable & Increase/Decrease in Trips (\%) \\
\hline Total Population & 1000 people increase & $5.4 \%$ increase \\
\hline zero-car households & $1 \%$ increase & $1.53 \%$ increase \\
\hline Households with two+ cars & $1 \%$ increase & $0.56 \%$ decrease \\
\hline Residential density (Persons/acre) & 1 person per acre increase & $0.46 \%$ increase \\
\hline $\begin{array}{l}\text { Network density (pedestrian-oriented } \\
\text { links) }\end{array}$ & 1 -unit increase & $1.21 \%$ increase \\
\hline $\begin{array}{l}\text { Proportion of people within } 1 / 2 \text { mile of } \\
\text { transit }\end{array}$ & $1 \%$ increase & $0.16 \%$ increase \\
\hline $\begin{array}{l}\text { Working-age population within } 45 \text { mins } \\
\text { auto travel time }\end{array}$ & 1000 people increase & $0.52 \%$ increase \\
\hline White Population & $1 \%$ increase & $0.87 \%$ increase \\
\hline $\begin{array}{l}\text { People with a Bachelor degree or higher } \\
\text { Station Capacity }\end{array}$ & $1 \%$ increase & $1.96 \%$ increase \\
\hline
\end{tabular}

In addition to the overall mixed effect model, we built Ordinary Least Squares (OLS) regression models for each individual city to look at the effects of micro-level built environment on bikeshare demand in more details and make comparisons among cities in terms of these effects. The results of the OLS models for individual cities are presented in Table 5. Similar to the local-level coefficients in our 
mixed effect model, results of the individual city OLS models show that most of the local level urban form variables are significantly correlated with the stations' demand. As expected, both station capacity and the percentage of days the station is active have significant positive correlation with the number of trips originated from each station in all six models. Looking at the effect of local-level built environment on bikeshare usage in all study areas, the results imply that higher population and employment densities and a higher level of mixed use development in the station area are all associated with higher number of trips originated from each station, except for a few insignificant coefficients. This is consistent with what previous research has suggested (Buck \& Buehler, 2012; Rixey, 2013; Faghih-Imani et al., 2014).

Table 5. OLS regression model results for individual cities

\begin{tabular}{|c|c|c|c|c|c|c|}
\hline \multicolumn{7}{|c|}{ Dependent variable: $\log$ (trips) } \\
\hline & $(1)$ & $(2)$ & (3) & $(4)$ & $(5)$ & (6) \\
\hline & Boston & Chicago & $\begin{array}{l}\text { Washington, } \\
\text { D.C. }\end{array}$ & Minneapolis & Philadelphia & $\begin{array}{l}\text { San Francisco \& } \\
\text { San Jose }\end{array}$ \\
\hline \multirow{2}{*}{$\begin{array}{l}\text { Zero-car popula- } \\
\text { tion }\end{array}$} & 0.541 & $0.573^{*}$ & $1.180^{* * *}$ & $1.176^{* * *}$ & 0.507 & $1.133^{* * *}$ \\
\hline & $(0.400)$ & $(0.294)$ & $(0.290)$ & $(0.407)$ & $(0.513)$ & $(0.368)$ \\
\hline \multirow{2}{*}{$\begin{array}{l}\text { 2plus-car popula- } \\
\text { tion }\end{array}$} & $-0.856^{*}$ & $-1.555^{* * *}$ & $-1.338^{* * *}$ & 0.562 & 0.610 & $-1.178^{* * *}$ \\
\hline & $(0.498)$ & $(0.346)$ & $(0.338)$ & $(0.351)$ & $(0.933)$ & $(0.385)$ \\
\hline \multirow{2}{*}{$\begin{array}{l}\text { Residential } \\
\text { density }\end{array}$} & 0.001 & $0.003^{* *}$ & 0.002 & $0.006^{* *}$ & $0.009^{* * *}$ & $0.005^{* *}$ \\
\hline & $(0.002)$ & $(0.001)$ & $(0.002)$ & $(0.003)$ & $(0.002)$ & $(0.002)$ \\
\hline \multirow{2}{*}{$\begin{array}{l}\text { Employment } \\
\text { density }\end{array}$} & 0.00004 & 0.0002 & $-0.001^{* * *}$ & -0.0005 & $0.001^{*}$ & 0.001 \\
\hline & $(0.0004)$ & $(0.0002)$ & $(0.0005)$ & $(0.001)$ & $(0.0003)$ & $(0.001)$ \\
\hline \multirow[t]{2}{*}{ Entropy } & 0.285 & 0.148 & -0.065 & $0.530^{* * *}$ & 0.342 & 0.339 \\
\hline & $(0.198)$ & $(0.125)$ & $(0.156)$ & $(0.167)$ & $(0.229)$ & $(0.207)$ \\
\hline \multirow{2}{*}{$\begin{array}{l}\text { Median house- } \\
\text { hold income }\end{array}$} & $0.004^{* *}$ & $0.007^{* * *}$ & $0.004^{* * *}$ & 0.003 & 0.005 & $0.008^{* * *}$ \\
\hline & $(0.002)$ & $(0.001)$ & $(0.001)$ & $(0.002)$ & $(0.003)$ & $(0.001)$ \\
\hline \multirow{2}{*}{$\begin{array}{l}\text { \%White popula- } \\
\text { tion }\end{array}$} & $1.404^{* * *}$ & $2.144^{* * *}$ & $1.496^{* * *}$ & $1.842^{* * *}$ & 0.485 & $0.689^{* *}$ \\
\hline & $(0.235)$ & $(0.160)$ & $(0.211)$ & $(0.232)$ & $(0.344)$ & $(0.281)$ \\
\hline \multirow[t]{2}{*}{ Network density } & $0.017^{* * *}$ & 0.006 & $0.009^{*}$ & -0.007 & $0.016^{* *}$ & 0.005 \\
\hline & $(0.005)$ & $(0.004)$ & $(0.005)$ & $(0.006)$ & $(0.007)$ & $(0.006)$ \\
\hline \multirow[t]{2}{*}{ Transit-shed jobs } & $0.270^{*}$ & $0.191^{* *}$ & $0.326^{* * *}$ & $0.523^{* * *}$ & $0.388^{*}$ & $-0.209^{*}$ \\
\hline & $(0.137)$ & $(0.093)$ & $(0.105)$ & $(0.143)$ & $(0.201)$ & $(0.122)$ \\
\hline \multirow{2}{*}{$\begin{array}{l}\text { Auto-commuter } \\
\text { population }\end{array}$} & $1.336 \mathrm{e}-05^{* * *}$ & $2.253 \mathrm{e}-06^{* * *}$ & $1.135 \mathrm{e}-05^{* * *}$ & $1.625 \mathrm{e}-05^{* * *}$ & $1.813 \mathrm{e}-06$ & $-2.272 \mathrm{e}-07$ \\
\hline & $(1.349 \mathrm{e}-06)$ & $(4.487 \mathrm{e}-07)$ & $(9.081 \mathrm{e}-07)$ & $(2.037 \mathrm{e}-06)$ & $(2.988 \mathrm{e}-06)$ & $(1.364 \mathrm{e}-06)$ \\
\hline \multirow[t]{2}{*}{ Station capacity } & $0.038^{* * *}$ & $0.067^{* * *}$ & $0.062^{* * *}$ & $0.063^{* * *}$ & $0.030^{* * *}$ & $0.062^{* * *}$ \\
\hline & $(0.012)$ & $(0.006)$ & $(0.008)$ & $(0.008)$ & $(0.011)$ & $(0.008)$ \\
\hline \multirow[t]{2}{*}{ Active-days } & $0.009^{* * *}$ & $0.013^{* * *}$ & $0.008^{* * *}$ & $0.014^{* * *}$ & $0.007^{* * *}$ & $0.007^{* * *}$ \\
\hline & $(0.0003)$ & $(0.0004)$ & $(0.001)$ & $(0.002)$ & $(0.001)$ & $(0.001)$ \\
\hline \multirow[t]{2}{*}{ Constant } & $-2.936^{* * *}$ & $-1.158^{* * *}$ & $-2.344^{* * *}$ & $-3.948^{* * *}$ & 1.866 & $2.749^{* * *}$ \\
\hline & $(0.599)$ & $(0.312)$ & $(0.410)$ & $(0.773)$ & $(1.445)$ & $(0.651)$ \\
\hline
\end{tabular}




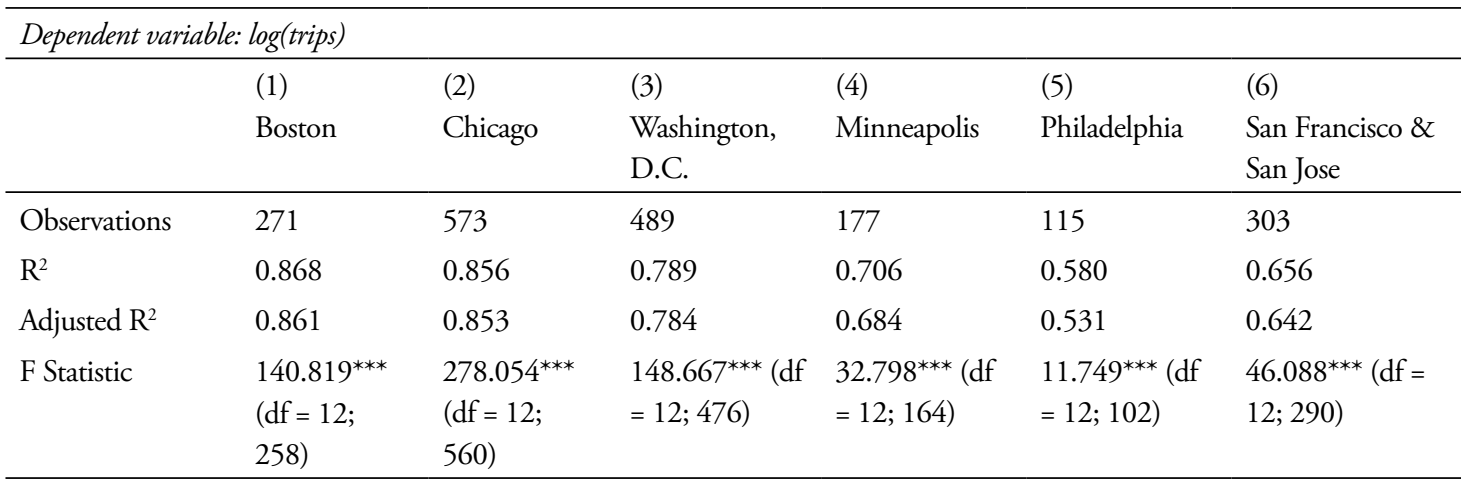

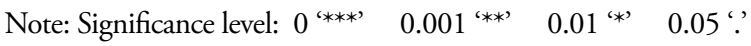

Similar to the mixed-effect model, in the individual cities OLS models, the proportion of zerocar households in the CBG has a positive relationship with the bikeshare demand in all study areas, although in Boston and Philadelphia the relationship is not statistically significant. The proportion of households with two or more automobiles has a significant negative association with the bikeshare trips in four cities, and insignificant relationships in the remaining two cases (Minneapolis and Philadelphia). These coefficients are consistent with findings of previous literature showing low car ownership and automobile accessibility are significant determinants of switching to other modes such as transit, walk, and bike, while higher automobile ownership encourages driving and reduces the share of other modes (Ding, Wang, Liu, Zhang, \& Yang, 2017; Nasri \& Zhang, 2019; Weinberger \& Goetzke, 2019). The bikeshare demand is higher in areas with higher proportion of white (except it is insignificant in the Philadelphia model) and higher income population (except it is insignificant in Minneapolis and Philadelphia models) who usually have lower access to private automobiles (Fishman, 2016; McNeil, Broach, \& Dill, 2018). This, in part might be related to the culture and partially due to the cost of the bikeshare system itself, which might prevent the low-income households (usually without a car) to adapt themselves to these new emerging technologies.

In terms of the effects of the network, results show that the higher the density of road network within a bikeshare station area, the higher the number of trips originated from that station in Boston, Washington, D.C., and Philadelphia, while the relationship is statistically insignificant in the remaining three cities. Job accessibility via transit is another contributing factor for the bikeshare demand in most of the study areas. As it is indicated in the Table 5, the proportion of CBG employment within $1 / 2$ miles of transit (transit-shed jobs) is significantly and positively correlated with the number of bikeshare trips originated from the stations located in a particular CBG, except in San Francisco \& San Jose model where the correlation is negative. On the other hand, Auto-commuter residents (the percentage of station area population within 45 minutes auto travel) is also significantly and positively correlated with the number of trips originated from stations in all but two cases of Philadelphia and San Francisco \& San Jose. Similar to the mixed-effect model, these results together show that multi-modal employment accessibility and higher population around stations both are important factors influencing the demand for bikeshare usage.

As aforementioned, the reason to construct these OLS models for each individual city was to investigate the effects of micro-level built environment on bikeshare in more details and make comparisons among cities. We do not claim one approach is preferred over the other. Instead, we are showing that it is important to understand the bikeshare demand within its context- i.e., by controlling for various sociodemographic and spatial characteristics of individual cities- in addition to analyzing the big picture, that is, the impact of regional level urban form on station-level bikeshare demand (see Tables 3 and 5). 


\section{$5 \quad$ Conclusion and recommendations}

This study investigated the influence of urban form on bikeshare demand in seven U.S. metropolitan areas with relatively large bikeshare systems. It provides overall useful insight into how and to what extent the built environment at different scales influences the bikeshare demand. Results suggest that regional level built environment characteristics, such as the overall level of mixed use development and the overall bike-friendliness are as effective on bikeshare usage as is the urban form at the local (station) level. However, most of the built environment measures at the metropolitan level lacked variation and did not show significant correlation with bike trips and thus were eliminated from the model. As a result, bikesharing is more influenced by the local-level urban form despite automobile trips and car ownership decision, which are found in the previous literature to be influenced by both local- and regional-level urban form (Nasri \& Zhang, 2012, 2014; Naess, 2011).

The results suggest that job accessibility via transit positively correlates to the bikeshare demand, similar to the existence of rail transit near bikeshare stations. This indicates that the relationship between bikeshare and transit is complementary. It is an expected outcome because having bikeshare facilities right next to rail transit stops would facilitate first-mile/last-mile access to transit and would encourage more transit ridership. Locating bikeshare stations near transit provides a better accessibility to various destinations, as usually transit stops are located in areas with high population and employment densities and provide better accessibility to destinations and public services (Daddio, 2012). On the other hand, these results also suggest that polycentric urban form and having employment distributed all around the metropolitan areas as opposed to concentrated in a large city center (i.e., monocentric urban form) would improve multimodal employment accessibility and ultimately would influence the use of bikeshare system and potentially other forms of emerging micro-mobility services in the future.

However, the current research has several limitations and identifies additional research possibilities. While the current mixed-effect model does capture both fixed and random effects, it has limited capability of addressing causality, as it does not have any individual-level travel and bikeshare usage data available. This data limitation prevents the present study and other past studies to look at how individuals with different sociodemographic background use the bikeshare systems, for what trip purposes, and for how long. Next, since the current analysis uses aggregate trip information for its purpose, it fails to take into account the effect of climate and a city's topography on bikesharing usage-even though it includes all the trips made within a one-year time window-as it is a station-level analysis rather than a trip-based analysis. Data limitation and the level of aggregation also prevents our study to take into account the effects of bike availability - i.e., the real-time number of bikes at the stations for checking out as well as the number of empty docks for returning — on bikeshare demand. Our study does not include such potential factors into the statistical analysis due to data limitation and its aggregate analysis scope. Certainly, including such additional variables would significantly enhance the predictability and validity of the current models, as these are important factors affecting the choice of bike as a transportation mode. Additional factors such as spatial and temporal tourism activity pattern would also influence demand differently within different regions and would serve as a potential future research topic. Moreover, the effect of regional-level built environment on bikeshare demand would be captured more comprehensively if the sample size was larger, by providing data on additional cities, with potentially different sizes, urban form patterns, bikeshare system's characteristics and size, and weather conditions. This would be possible specifically by increasing the variation of macro-level variables that are included in the models.

Finally, the emergence of dockless bikeshare and scooter-share systems in many cities across the country creates several new research questions. Future research could be focused on a better understanding of the relationships between the two conventional and dockless bikeshare systems, the influence of 
bikesharing -either dockless or station-based-on other modes, such as driving and transit, and the effect of built environment on bikeshare usage as a whole with the presence of dockless systems.

\section{Acknowledgements}

This research was partially supported by the Maryland Transportation Institute and National Center for Smart Growth at the University of Maryland. We thank Dr. Ralph Buehler from the Virginia Tech, who provided insight and expertise that greatly assisted the research. We also appreciate Dr. Sepehr Ghader for his help with the statistical modeling and interpretations as well as the anonymous reviewers whose comments helped to greatly improve the paper. The authors are solely responsible for the content of this paper. 


\section{References}

Bachand-Marleau, J., Lee, B., \& El-Geneidy, A. (2012). Better understanding of factors influencing likelihood of using shared bicycle systems and frequency of use. Transportation Research Record: Journal of the Transportation Research Board, 2314, 66-71.

Bates, D., Maechler, M., Bolker, B., Walker, S., Christensen, R. H. B., Singmann, H., ... \& Scheipl, F. (2012). Package 'Ime4'. CRAN. R Foundation for Statistical Computing, Vienna, Austria.

Biehl, A., Ermagun, A., \& Stathopoulos, A. (2018). Community mobility MAUP-ing: A socio-spatial investigation of bikeshare demand in Chicago. Journal of Transport Geography, 66, 80-90.

Buck, D., \& Buehler, R. (2012). Bike lanes and other determinants of capital bikeshare trips. Paper presented at the 91st Transportation Research Board annual meeting, Washington, DC.

Buehler, R. (2011). Determinants of transport mode choice: A comparison of Germany and the USA. Journal of Transport Geography, 19(4), 644-657.

Christian, H. E., Bull, F. C., Middleton, N. J., Knuiman, M. W., Divitini, M. L., Hooper, P., \& GilesCorti, B. (2011). How important is the land-use mix measure in understanding walking behavior? Results from the RESIDE study. International Journal of Behavioral Nutrition and Physical Activity, 8(1), 55.

Daddio, D. W. (2012). Maximizing bicycle sharing: An empirical analysis of capital bikeshare usage (Doctoral dissertation). University of North Carolina, Chapel Hill, NC.

DeMaio, P. (2009). Bike-sharing: History, impacts, models of provision, and future. Journal of Public Transportation, 12(4), 3.

Ding, C., Wang, D., Liu, C., Zhang, Y., \& Yang, J. (2017). Exploring the influence of built environment on travel mode choice considering the mediating effects of car ownership and travel distance. Transportation Research Part A: Policy and Practice, 100, 65-80.

El-Assi, W., Mahmoud, M. S., \& Habib, K. N. (2017). Effects of built environment and weather on bike sharing demand: A station level analysis of commercial bike sharing in Toronto. Transportation, 44(3), 589-613.

Faghih-Imani, A., Eluru, N., El-Geneidy, A. M., Rabbat, M., \& Haq, U. (2014). How land-use and urban form impact bicycle flows: Evidence from the bicycle-sharing system (BIXI) in Montreal. Journal of Transport Geography, 41, 306-314.

Fishman, E. (2016). Bikeshare: A review of recent literature. Transport Reviews, 36(1), 92-113.

Frank, L. D., Schmid, T. L., Sallis, J. F., Chapman, J., \& Saelens, B. E. (2005). Linking objectively measured physical activity with objectively measured urban form: Findings from SMARTRAQ. American Journal of Preventive Medicine, 28(2), 117-125.

Gebhart, K., \& Noland, R. B. (2014). The impact of weather conditions on bikeshare trips in Washington, DC. Transportation, 41(6), 1205-1225.

Gehrke, S. R., \& Welch, T. F. (2019). A bikeshare station area typology to forecast the station-level ridership of system expansion. Journal of Transport and Land Use, 12(1), 221-235.

Guan, C., Srinivasan, S., \& Nielsen, C. P. (2019). Does neighborhood form influence low-carbon transportation in China? Transportation Research Part D: Transport and Environment, 67, 406-420.

Hampshire, R. C., \& Marla, L. (2012). An analysis of bike sharing usage: Explaining trip generation and attraction from observed demand. Paper presented at the 91st Annual meeting of the Transportation Research Board, Washington, DC.

Jäppinen, S., Toivonen, T., \& Salonen, M. (2013). Modelling the potential effect of shared bicycles on public transport travel times in Greater Helsinki: An open data approach. Applied Geography, 43, $13-24$.

Kuzmyak, J. R., Walters, J., Bradley, M., \& Kockelman, K. M. (2014). Estimating bicycling and walking 
for planning and project development: A guidebook (NCHRP Report 770). Washington, DC: National Cooperative Highway Research Program.

Le, H. T., Buehler, R., \& Hankey, S. (2019). Have walking and bicycling increased in the US? A 13-year longitudinal analysis of traffic counts from 13 metropolitan areas. Transportation Research Part D: Transport and Environment, 69, 329-345.

Ma, T., Liu, C., \& Erdoğan, S. (2015). Bicycle sharing and public transit: does Capital Bikeshare affect Metrorail ridership in Washington, D C? Transportation Research Record, 2534(1), 1-9

Manson, S., Schroeder, J., Van Riper, D., Kugler, T., \& Ruggles, S. (2020) IPUMS National Historical Geographic Information System (Version 15.0) [dataset]. Minneapolis, MN: IPUMS. Retrieved from http://doi.org/10.18128/D050.V15.0

Martin, E. W., \& Shaheen, S. A. (2014). Evaluating public transit modal shift dynamics in response to bikesharing: A tale of two US cities. Journal of Transport Geography, 41, 315-324.

Mateo-Babiano, I., Bean, R., Corcoran, J., \& Pojani, D. (2016). How does our natural and built environment affect the use of bicycle sharing? Transportation Research Part A: Policy and Practice, 94, 295-307.

McNeil, N., Broach, J., \& Dill, J. (2018). Breaking barriers to bike share: Lessons on bike share equity. ITE Journal, 88(2), 31-35.

Morency, C., Trépanier, M., Faucher, J., Páez, A., \& Verreault, H. (2017). Modelling bikesharing usage in Montreal over 6 years (No. CIRRELT-2017-33). Montreal, Canada: Interuniversity Research Center on Enterprise Networks, Logistics and Transportation.

Muarer, L. K. (2011). Suitability study for a bicycle sharing program in Sacramento, California. Chapel Hill, NC: University of North Carolina at Chapel Hill, Department of City and Regional Planning.

Naess, P. (2011). 'New urbanism' or metropolitan-level centralization? A comparison of the influences of metropolitan-level and neighborhood-level urban form characteristics on travel behavior. Journal of Transport and Land Use, 4(1), 25-44.

Nair, R., Miller-Hooks, E., Hampshire, R. C., \& Bušić, A. (2013). Large-scale vehicle sharing systems: Analysis of Vélib'. International Journal of Sustainable Transportation, 7(1), 85-106.

Nasri, A. A. (2016). The influence of urban form at different geographical scales on travel behavior: Evidence from US cities (Doctoral dissertation). University of Maryland, College Park, MD.

Nasri, A., \& Zhang, L. (2012). Impact of metropolitan-level built environment on travel behavior. Transportation Research Record: Journal of the Transportation Research Board, 2323, 75-79.

Nasri, A., \& Zhang, L. (2014). Assessing the impact of metropolitan-level, county-level, and local-level built environment on travel behavior: Evidence from 19 US urban areas. Journal of Urban Planning and Development, 141(3), 04014031.

Nasri, A., \& Zhang, L. (2019). Multi-level urban form and commuting mode share in rail station areas across the United States: A seemingly unrelated regression approach. Transport Policy, 81, 311-319.

Nielsen, T. A. S., \& Skov-Petersen, H. (2018). Bikeability-Urban structures supporting cycling. Effects of local, urban and regional scale urban form factors on cycling from home and workplace locations in Denmark. Journal of Transport Geography, 69, 36-44.

Parkin, J., Wardman, M., \& Page, M. (2008). Estimation of the determinants of bicycle mode share for the journey to work using census data. Transportation, 35(1), 93-109.

Rajamani, J., Bhat, C. R., Handy, S., Knaap, G., \& Song, Y. (2003). Assessing impact of urban form measures on nonwork trip mode choice after controlling for demographic and level-of-service effects. Transportation Research Record, 1831(1), 158-165.

Ranaiefar, F., \& Rixey, R. A. (2016). Bike sharing ridership forecast using structural equation modeling. Paper presented at the Transportation Research Board 95th Annual Meeting (No. 16-6573), Washington, DC. 
Rixey, R. (2013). Station-level forecasting of bikesharing ridership: Station network effects in three US systems. Transportation Research Record: Journal of the Transportation Research Board, 2387, 46-55.

Rodríguez, D. A., \& Joo, J. (2004). The relationship between non-motorized mode choice and the local physical environment. Transportation Research Part D: Transport and Environment, 9(2), 151-173.

Schrank, D., \& Lomax, T. (2007). The 2007 urban mobility report. College Station, TX: Transportation Institute, Texas A\&M University.

Shaheen, S., Cohen, A., \& Martin, E. (2013). Public bikesharing in North America: Early operator understanding and emerging trends. Transportation Research Record: Journal of the Transportation Research Board, 2387, 83-92.

Shaheen, S., Guzman, S., \& Zhang, H. (2010). Bikesharing in Europe, the Americas, and Asia: past, present, and future. Transportation Research Record: Journal of the Transportation Research Board, 2143, 159-167.

Team, R. C. (2012). R: A language and environment for statistical computing. 2012. Vienna, Austria: R Foundation for Statistical Computing, 10.

Tingting, L., Li, L., \& Wei, L. (2011). Analysis of public bicycles' impact on residents' trip chain. In Proceedings 2011 International Conference on Transportation, Mechanical, and Electrical Engineering (TMEE) (pp. 182-185). IEEE.

Tran, T. D., Ovtracht, N., \& d'Arcier, B. F. (2015). Modeling bike sharing system using built environment factors. Procedia CIRP, 30, 293-298.

Wang, X., Lindsey, G., Schoner, J. E., \& Harrison, A. (2016). Modeling bike share station activity: Effects of nearby businesses and jobs on trips to and from stations. Journal of Urban Planning and Development, 142(1), 04015001.

Weinberger, R., \& Goetzke, F. (2019). Automobile ownership and mode choice: Learned or instrumentally rational? Travel Behavior and Society, 16, 153-160.

Younes, H., Nasri, A., Baiocchi, G., \& Zhang, L. (2019). How transit service closures influence bikesharing demand: Lessons learned from SafeTrack project in Washington, DC metropolitan area. Journal of Transport Geography, 76, 83-92.

Younes, H., Zou, Z., Wu, J., \& Baiocchi, G. (2020). Comparing the temporal determinants of dockless scooter-share and station-based bike-share in Washington, DC. Transportation Research Part A: Policy and Practice, 134, 308-320.

Zhang, L., Hong, J., Nasri, A., \& Shen, Q. (2012). How built environment affects travel behavior: A comparative analysis of the connections between land use and vehicle miles traveled in US cities. Journal of Transport and Land Use, 5(3), 40-52. 